\title{
TRENDS AND DEVELOPMENT IN CHIRONOMID PALAEOECOLOGY: SUMMARY FROM THE $9^{\mathrm{TH}}$ WORKSHOP ON SUBFOSSIL CHIRONOMIDAE
}

\author{
Klaus Peter Brodersen ${ }^{1}$, Gaute Velle ${ }^{2} \&$ Nina S. Reuss ${ }^{1}$ \\ ${ }^{1}$ Freshwater Biological Laboratory, Biological Institute, University of Copenhagen, Denmark. \\ kpbrodersen@bio.ku.dk,nreuss@bio.ku.dk \\ ${ }^{2}$ Bergen Museum, University of Bergen, Norway. nzlgv@uib.no
}

The 9th workshop on Subfossil Chironomidae was held at the Biological Institute, University of Copenhagen on May 4-6, 2009. There were 27 palaeo-chironomid researchers present, representting 14 different nationalities (Fig. 1, group photo). The purpose with these workshops is to exchange ideas and to have critical and fruitful discussions about topics ranging from larval identification to ecological interpretation whether people are working with subfossil or contemporary data. Problems and progresses in chironomid palaeoecology are discussed among people with their fingers deep in the mud, and the informal presentations give a fine overview of current state-of-the-art research and development.

The workshop was organised into six sessions with oral presentations, one session of general discussion and a one-day field excursion. The field excursion on the first day took us around to the North Zealand birch forest in full leaf. We had a short lunch break at the Freshwater Biological Laboratory belonging to the University of Copenhagen in the town of Hillerød. At the shore of Lake Esrum, the laboratory’s Grand-Old-Man,
Pétur Jónasson (born 1920) (Fig. 2), gave a fine summary of his illustrious work on life-cycles, respiration, secondary production and benthicpelagic coupling of Chironomus anthracinus in Lake Esrum (Jónasson 1972).

With three sessions under the climate topic, it is evident that chironomid-inferred temperature reconstruction is still a central issue. Subfossil chironomids are still used as the primary quantitative climate indicator in multi-proxy studies of e.g., Early Weichselian, as presented by Stefan Engels, and Late Glacial sediments, as presented by Mateusz Plociennik. New quantitative temperature models are being developed and improved. Results of two merged European data sets were presented by Steve Brooks, a Finnish data set was shown by Tomi Luoto, and two independent data sets from Northern Russia are being developed and were presented by Larisa Nazarova and Angela Self. Along with these studies, preliminary stratigraphies and taxonomic problems were addressed by Verana de Hoog. A novel idea from Angela Self was to incorporate "continentality" into

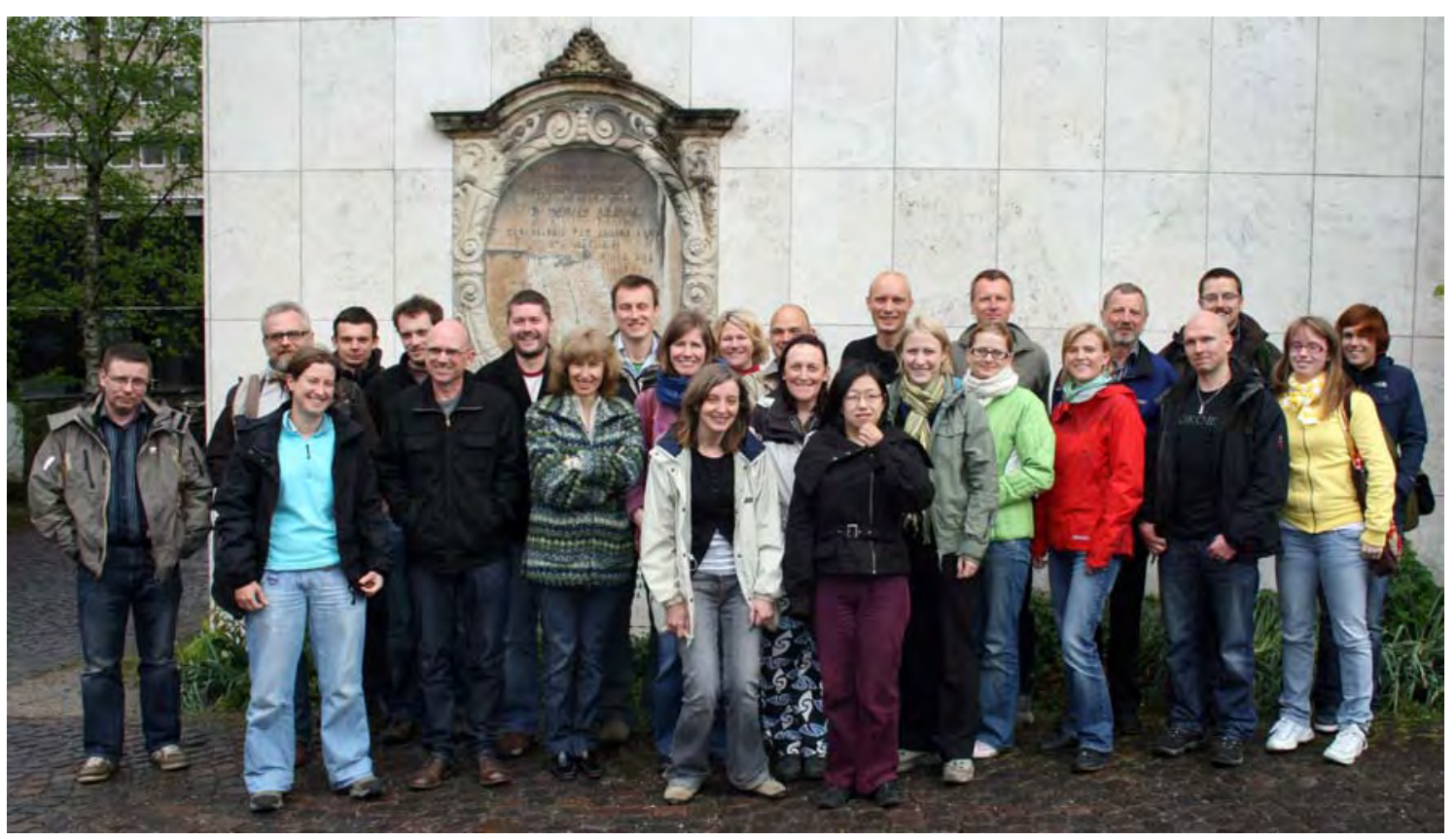

Figure 1. Participants at the workshop. Photo: Katrine Kongshavn. 
the quantitative models. Down-core continentality reconstructions from the Putoran Plateau suggest a lengthening of the growing season despite relatively constant temperature over the 1950s2000.

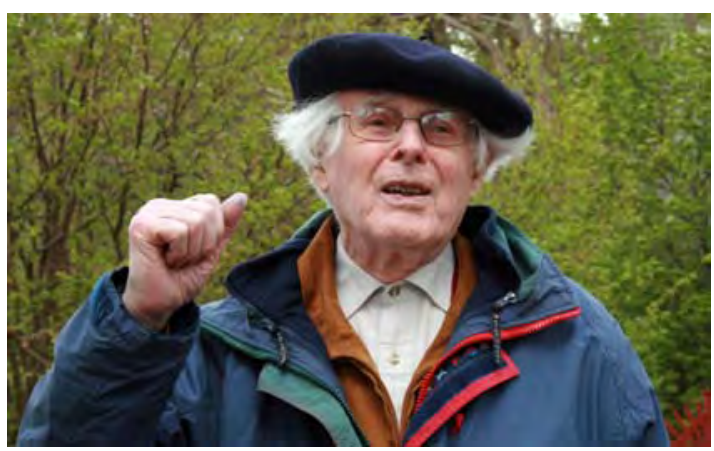

Figure 2. Professor Pétur M. Jónasson speaking about Chironomus population dynamics at the shore of Lake Esrum. Photo: Katrine Kongshavn.

Analyses of recent climate change over the last few hundred years were presented from the far north in Spitsbergen (Katrine Kongshavn) to the south in Patagonia (Peter Langdon). Comparisons to instrumental and independent records (e.g., known past fluctuations in glacier extent), are used in order to assess the potential for reconstructing accurately climate change over longer (millennial scale) time periods (Peter Langdon). High-resolution analyses from annually varved sediments are likewise used along with instrumental records in evaluation of model performance in Switzerland (Isabelle Larocque).

Studies of past environmental change in the Bolivian Andes were presented by Joseph J. Williams. In this project they are tracing the natural history of an endangered woodland ecosystem in order to evaluate if the patchy distribution of Polylepis observed today is a relict of past more widespread dominance and if the current distribution is human and/or climate driven. The chironomids are used as independent climate proxies.

Human induced environmental impacts, aside from climate change, were in focus of many studies. Enrichment (eutrophication) effects of human settlement were discussed from Northern Ireland by Naomi Holmes. Models across Europe have suggested that events such as the adoption of agriculture in Europe are climatically driven and hints of this relationship are present in existing North Mayo data. The environmentally sensitive nature of the area means that North Mayo is an ideal case study for the relationships between climate change and changes in human settlement.
From Africa, Bob Rumes demonstrated a clear evidence for anthropogenic presence and influence on the landscape in Western Uganda dating back 2000 years. Although there were pronounced natural climate variations in the area, the effect of these is not always clear and, at times, difficult to distinguish from anthropogenic changes. Complex ecological responses to eutrophication and recent climate in Denmark were analysed against environmental monitoring data using fine interval sampling (Wing Wai Sung). Recent human impact on lake food webs by e.g., introduction of fish is also a new field in chironomid palaeolimnology. Such studies are carried out in subalpine lakes in France (Virgile Baudrot), in south Swedish lakes (Kimmo Tolonen) and in crater lakes at the Azores (Klaus P. Brodersen). The role of natural changes, such as succession in primary producers, food resources, oxygen conditions, intra- and interspecific competition and changes in benthic communities is studied by Nina Reuss. She is studying stable isotope signatures on the most common chironomid taxa from West Greenland as well as on their potential food resources. Successful results will allow down-core inference of changed food-web structures and lake dynamics.

Examination of fossil midge assemblages from surface sediments of small shallow lakes in Finland took us back to basics in interpretation of chironomid palaeolimnology. Tomi Luoto presented multi- and intra-lake studies to emphasize that the controlling environmental factors are scale dependent from temperature over lake depth to hypolimnetic oxygen conditions. Intra-lake dataset from eastern Finland showed that the most important environmental factors controlling midge distribution within a lake basin were river contribution, water depth and submerged vegetation patterns. It also appeared that the fossil midge assemblages represented fauna that lived in close proximity to the sampling sites thus enabling investigation of intra-lake gradients in midge assemblages.

Novel studies on the potential of using subfossil chironomids as indicators of palaeoflow regimes were discussed by Lynda Howard. Chironomidae, identified to species level where possible, could be classified into groups of "Lotic invertebrate Index for Flow Evaluation”. This information was used to reconstruct the palaeoflow regime of a river and associated changes to in-stream habitats.

Improvement of subfossil taxonomy and identification has always been a central subject in these workshops. Boris Ilyashuk presented 
current knowledge and palaeoecological perspectives regarding the genus Pseudodiamesa. The aim was to clarify the morphological characters of head capsules of the Pseudodiamesa larvae which can be clearly visible within subfossil remains and reliable used for an identification of the subgeneric morphotypes. A short summary of the zoogeography and ecology of Pseudodiamesa species was also given which is very helpful in palaeoecological interpretation of subfossil records.

A general discussion on palaeoenvironmental inferences at the extremes of the environmental gradient was introduced and chaired by Gaute Velle. The modern calibration data set lake samples include chironomid head capsules and concurring environmental variables. However, it is not straightforward to use the calibration data set to infer environmental variables that are near the lower or upper end of the gradient captured by the modern data. Gaute Velle pointed out typical challenges, such as:

(1) The edge effect. Inferring variables at the end of the gradient must be done with caution. The so-called 'edge effect' caused by a truncation of the taxa responses, results in a tendency to pull the predicted values towards the mean of the environmental range in the calibration data set.

(2) Few modern taxa at the extremes. Since there often are more lakes in the mid-range of the calibration data sets, fewer taxa are captured from the gradient extremes. Hence, the response functions for the taxa at the extremes are less confident as they are based on fewer observations.

(3) Low fossil diversity. Sites or time periods with extreme environments may have additional challenges as these often have a low diversity. When there is a low diversity in the fossil assemblage, the taxa that are present influence the palaeoenvironmental inference to a large extent and the inference may be more prone to bias caused by inadequate response functions or to stochastic variables.

(4) Low abundance. Sites or time periods at extreme environments often have a low abundance of chironomids. Any quantitative palaeoenvironmental inference should be based on $>50$ head capsules.

(5) Pioneer assemblages. In extreme habitats, such as newly formed cold proglacial lakes, the pioneer fauna may be in disproportion with concurrent environments because they are specialist pioneers or because they are opportunists.

In summary, the workshop was very fruitful and inspiring. Chironomid palaeoecology is still growing, but also developing away from blind routine temperature reconstructions of past climate conditions. In the summary of the previous workshop in Reykjavik, Langdon et al. (2007) stated: “...in other words palaeoecological simplicity may need to be considered more carefully in the face of ecological complexity". Many discussions at the workshop clearly demonstrated that other human and natural impacts, aside from climate and temperature, are affecting the fossil assemblages, and that many of these parameters can be successfully interpreted. It is also positive that many from the new generation of chironomid palaeoecologists are going back to basics to critically assess the strengths and weaknesses of their models and methods. We strongly encourage such efforts and also efforts made to integrate neo- and paleolimnological approaches to refine interpretations of environmental change (e.g., Saros 2009). Such efforts are important in order to understand the biological mechanisms driving the species distribution and abundance.

We thank all for active participation and constructive discussions. The next workshop on subfossil chironomidae is arranged by Gaute Velle in Bergen, Norway, in May 2011.

\section{References}

Jónasson, P.M. 1972. Ecology and production of profundal benthos in relation to phytoplankton in Lake Esrom. - Oikos Supplementum 14: 1148.

Langdon, P., Holmes, N., Stefánsson, S.M., Hannesdóttir, E. and Axford, Y. 2007. The 8th European Subfossil Chironomid Workshop, Reykjavik 7-8th May 2007. - Chironomus newsletter on Chironomidae research 20: 1013.

Saros, J. 2009. Integrating neo- and paleolimnological approaches to refine interpretations of environmental change. - Journal of Paleolimnology 41: 243-252. 